\title{
ESTUDIOS
}

\section{La misión de la Iglesia en el mundo actual}

\section{Joaquín Perea González'}

Resumen: el tema de la misión de la Iglesia según el documento conciliar Gaudium et spes es abordado en la perspectiva global de la "recepción" del Concilio. El estudio empieza con un resumen de lo específico y nuevo de Gaudium et spes en su contexto histórico y los cambios de aquella época para la Iglesia católica que, "estupefacta" miraba al mundo; a continuación se estudia la gestación de Gaudium et spes, haciéndose una valoración de los aspectos positivos y negativos, así como un primer balance posconciliar. La relectura de la Constitución Gaudium et spes en una Iglesia transformada en un mundo muy cambiado conduce a la reflexión eclesiológica sobre la recepción y la tradición. Estas expresan una crisis en la relación de la Iglesia con el mundo, así como los cambios en la concepción teológica de mundo. La relectura se hace a la luz de la recepción del documento, para después replantear el tema de la recepción en sí misma. En la corriente de la reforma de la Iglesia, la tradición es entendida como proceso creativo, por tanto abierto a algunas pistas sobre los contornos del ser eclesial y los nuevos modelos sociales del futuro.

Palabras clave: Eclesiología, Gaudium et spes, Iglesia, mundo, pastoralidad, recepción, reforma eclesial, tradición.

\section{The mission of the Church in the modern world}

Abstract: The subject of the mission of the Church according to the Council document Gaudium et spes is addressed in the overall perspective of the "reception" of the Council. The study begins with a summary of the specific and new Gaudium et spes in its

\section{La mission de l'Eglise dans le monde moderne}

Résumé: Le sujet de la mission de l'Eglise, selon le document conciliaire Gaudium et spes est abordé dans la perspective globale de la «réception» du Concile. L'étude commence par un résumé de ce qu'il y a du spécifique et du nouveau de Gaudium et spes

' Profesor de Teología, jubilado. Presbítero de Bilbao. Presidente del consejo de Iglesia viva. Revista de Pensamiento Cristiano, Valencia. jperea@idtp.org 
historical context and the changes of the time for the Catholic Church, "stupefied" looked at the world; then the gestation of Gaudium et spes is studied, making an assessment of the positive and negative aspects, as well as a first post-conciliar balance. Rereading the Constitution Gaudium et spes in a church transformed into a world much changed leads to the ecclesiological reflection upon receiving and tradition. These express a crisis in the relationship between the Church and the world, as well as changes in the theological conception of the world. Rereading is made in the light of the receipt of the document, then reframing the reception itself. In the current reform of the Church, tradition is understood as a creative process, thus open to some clues about the contours of being ecclesial and new social models of the future.

Keywords: Ecclesiology, Gaudium es spes, church, world, pastorality, reception, church reform, tradition.

Recibido: 16 de julio de 2015. dans son contexte historique et une époque de changements pour l'Eglise catholique, " stupéfaite » regarda le monde; puis la gestation de Gaudium et spes est étudié, ce qui rend une évaluation des aspects positifs et négatifs, ainsi qu'un premier bilan postconciliaire. Relire la constitution Gaudium et spes dans uneéglise transformée en un monde qui a beaucoup changé conduit à la réflexion ecclésiologique lors de la réception et de la tradition. Ceux-ci expriment une crise dans les relations entre l'Église et le monde, ainsi que des changements dans la conception théologique du monde. La relecture est faite à la lumière de la réception du document, puis recadrant la réception elle-même. Dans la réforme actuelle de l'Église, la tradition est comprise comme un processus créatif, donc ouvert à quelques indices sur les contours de l'être ecclésial et de nouveaux modèles sociaux de l'avenir.

Mots clé: Ecclésiologie, Gaudium et spes, Église, monde, pastoralité, réception, réforme de l'Église, tradition. 


\section{Una Iglesia que mira al mundo}

Los aniversarios pueden ser ambivalentes. También los simposios teológicos que los conmemoran. La afirmación es válida asimismo para la celebración de los documentos del Concilio Vaticano Il a los cincuenta años de su clausura. Porque en este punto nos enfrentamos además a una cuestión eclesiológica de suma gravedad que es preciso abordar: la recepción del Concilio.

Para unos, aunque es verdad que el Vaticano Il fue una ruptura, lo que después de él importa es la vida de cada día. Para otros la recepción del Concilio todavía no ha empezado verdaderamente ${ }^{2}$. Como afirmaba un antiguo padre conciliar, obispo auxiliar de Viena, el papa Juan XXIII quiso dar un gran salto hacia delante, pero hasta ahora solo hemos logrado dar unos primeros pasitos. Muchas cosas, quizá las más importantes, quedan por hacer, para llegar a una renovación desde lo profundo y desde las fuentes, que sea al mismo tiempo respuesta a los signos de los tiempos. ${ }^{3}$ Esta consideración pone en el punto de mira no solo a quienes dirigen la lglesia, sino a la mayoría de los creyentes, los laicos, que no pertenecen al grupo dirigente, pero que son los sujetos decisivos para la realización de la reforma conciliar. La "ruptura" conciliar no concierne únicamente a estructuras e instituciones internas a la Iglesia, sino, en un sentido global, a toda la comunidad cristiana en cuanto enviada al mundo. ¿Cómo realizar la exigencia irrenunciable de anunciar el evangelio siendo conscientes de que dicho anuncio no es auténtico sin una confrontación leal con la persona humana y su patrimonio cultural, rico en valores e incluso en vestigios del evangelio, y si no es "pobre", es decir, si no confía en privilegios sociales?

\section{I.I. La recepción del Concilio}

Esto supuesto, es obvio que el análisis de la recepción de este Concilio en la Iglesia posconciliar no puede efectuarse solamente desde la perspectiva de las cuestiones, por así decir, internas a ella, como podría hacerse, por ejemplo, a través de un análisis del proceso seguido en estos cincuenta años en la aplicación de la enseñanza de la constitución sobre la Iglesia Lumen gentium. Con ello se

\footnotetext{
2 W. KASPER (1989) Teología e Iglesia, Barcelona, Herder, 401-416.

${ }^{3}$ H. KRÄTZL (1998) Im Sprung gehemmt. Was mir nach dem Konzil noch alles fehlt, Mödling (St. Gabriel), 288; H. KRÄTZL (2012) Das Konzil - ein Sprung vorwärts. 50 Jahre Zweites Vatikanisches Konzil. Ein Zeitzeuge zieht Bilanz, Innsbruck, 89
} 
olvidaría que hay otro documento fundamental de carácter eclesiológico que es precisamente la Gaudium et spes. Siendo la última constitución conciliar aprobada, le debemos reconocer una prioridad criteriológica en lo que se refiere a la recepción del Concilio. Es el documento más voluminoso que jamás haya aprobado un concilio. En su planteamiento y método es nuevo y desacostumbrado, de tal forma que la deliberación y formulación fue particularmente difícil. Gaudium et spes ha experimentado también la mayor crítica de todos los textos del Concilio, ya en el aula conciliar y más aún después de 1965. No pocos han hecho a este documento responsable de la profunda crisis que ha sacudido la vida de la Iglesia en la época siguiente.

Solo estas valoraciones ya son motivo suficiente para que después de cincuenta años nos aproximemos a su texto de manera interesada. El posicionamiento de la lglesia católica en el mundo moderno es un tema fundamental. La Iglesia en su conjunto apenas se ha dado cuenta de lo que significa dar testimonio del evangelio en una época secularizada con todas sus facetas y contradicciones. La celebración de este cincuentenario es una buena oportunidad para poner sobre la mesa las cuestiones pendientes.

En lo que sigue a continuación empezaré haciendo un resumen de lo específico y novedoso de la Gaudium et spes, situándome en el contexto histórico de hace cincuenta años. Habrá que ver sobre todo los cambios de época que marcó para la Iglesia católica el documento del que hablamos. Será necesario explayar algunas consideraciones que derivan del balance posconciliar, habida cuenta, como no puede ser de otra manera, de los cambios que han sucedido a lo largo de estos años in mundo huius temporis. La relectura de la Constitución en una Iglesia transformada que actúa en un mundo muy cambiado conduce a la reflexión eclesiológica sobre la recepción y la tradición, para terminar sugiriendo alguna pista sobre los contornos del ser eclesial se diseñan para el futuro en este contexto.

Con la llegada del papa Francisco esta cuestión adquiere actualidad: él ha prevenido contra la tendencia a colocar al Concilio en el museo y al Espíritu Santo en una tarima para quedarnos tranquilos. Quien rechaza la renovación y la reforma, peca; quien se mantiene exclusivamente en lo acostumbrado, se enfrenta al Espíritu Santo.

\subsection{Una iglesia estupefacta mira al mundo}

No se puede prescindir del contexto mundial en el que se desarrollaron los trabajos preparatorios de la Constitución pastoral, porque solo en aquel contexto se pueden captar las razones más profundas que han estado en su origen y han determinado 
su redacción. El Concilio no era convocado solo para resolver dificultades internas de la lglesia, sino antes que nada para afrontar los problemas que la rápida evolución de la historia había generado en el mundo moderno. La relación con él estaba presente y explícita en las intenciones de Juan XXIII: la constatación de que había llegado al umbral de un cambio de época, imponía a la lglesia nuevas tareas.

¿Cuáles eran éstas? ¿ ¿qué podía y debía hacer la lglesia frente a la crisis existente? Los problemas que caracterizaban al mundo en vísperas del Concilio eran graves. Se habían debilitado los valores del espíritu; el crecimiento económico, al tiempo que acrecentaba los desequilibrios, las desigualdades sociales y la pobreza, empujaba al materialismo práctico; se estaba difundiendo un ateísmo militante, los problemas de la familia se hacían cada día más complejos, los derechos humanos, la libertad y la paz de modo particular estaban sobre el tapete de las reuniones internacionales. Era necesario ayudar al mundo a superar esta crisis, sin juzgarlo con pesimismo, sino al contrario, descubriendo en él, como "signos de los tiempos", aquellos indicios que podían suscitar esperanzas acerca de la suerte de la lglesia y de la humanidad.

Si se quiere encontrar un punto de referencia en el que contextualizar históricamente el Concilio, parece que deba ser individuado en la segunda guerra mundial y todo lo que la precedió. La guerra había sido el trágico fracaso de "un mundo"; después de ella el mundo era verdaderamente otra cosa muy distinta: las personas, la sociedad, las instituciones no eran las mismas.

En los años sucesivos a la guerra había cambiado totalmente la cultura, había surgido en muchos países una generación nueva que quería romper con el pasado y quería construir un mundo distinto. Existía una voluntad de participación que involucraba un poco a todos. En muchos países se experimentaban nuevas formas democráticas. Nuevos modelos sociales y nuevas mitologías se confrontaban con tonos encendidos. Crecía la convicción de la importancia del compromiso en favor de los propios derechos para lograr mayor libertad.

¿Cuáles eran en el interior de la lglesia las opiniones sobre esta realidad en ebullición y fermento? Puede decirse, esquematizando, que eran dos las posiciones que emergían en el episcopado que llegaba al Concilio representando a las Iglesias locales: una miraba al mundo con actitud de temor y hostilidad, otra consideraba con preocupación la distancia creciente entre el mundo y la lglesia.

La corriente de la hostilidad recuperaba ampliamente los esquemas ideológicos de la batalla antimodernista de comienzos del siglo XX: la crisis del mundo moderno 
era ante todo el fruto de su alejamiento de Dios, de la exaltación de la razón y del espíritu crítico levantado contra la fe y contra la lglesia ${ }^{4}$. De aquí derivaban todos los males, todas las tensiones de la vida internacional y los desórdenes de la sociedad en el interior de todos los países. El comunismo era su expresión más peligrosa, como demostraba el ateísmo militante y las persecuciones religiosas en Rusia y en los estados soviéticos.

También en aquella parte del mundo que se proclamaba libre, la modernidad presentaba caracteres amenazantes. La sociedad opulenta y de consumo se había revelado como un empuje potente para aquel proceso de secularización que arrancaba cada vez más a los fieles de la religión y de la lglesia. Desde este punto de vista el objetivo del Concilio debía ser precisamente el de reafirmar la verdad católica y defender el depósito de fe que le ha sido confiado contra los errores modernos.

Ahora bien, entre los padres conciliares la actitud ante el mundo moderno no se manifestaba solo como ideología de condena. La conciencia de la distancia cada vez mayor que separaba a la lglesia del mundo moderno, la percepción del alejamiento de las masas de la práctica religiosa, el desvanecerse de la dimensión espiritual en la vida de las personas y de la sociedad, suscitaba entre otros obispos una difusa ansia pastoral que se traducía en la búsqueda de estrategias de apostolado nuevas y más adecuadas a los tiempos modernos.

Quizá no fueran conscientes de que la renovación de los métodos pastorales conllevaba un cambio más profundo de toda la sustancia eclesial. De hecho el acontecimiento conciliar dio lugar a una renovación completamente inesperada respecto a lo que podía suponerse en sus vísperas. En general podemos decir que su respuesta estaba fundada en una reconsideración a fondo de la relación de la Iglesia tanto con la historia y como con la tradición, en una comprensión menos jurídica y más sacramental de sí misma y en la reflexión sobre el propio papel en la historia de la salvación. La interpretación de la Gaudium et spes en perspectiva histórica debe considerar todo esto que acabamos de indicar someramente.

${ }^{4}$ Cf J. PeREA (2007) "En el centenario de la condenación del modernismo. Una crisis que no se cerró y que no se cerrará": Iglesia Viva 41, 87-109. 


\section{La difícil gestación de la constitución pastoral}

El origen de la constitución pastoral está estrechamente vinculado con la historia del mismo Concilio ${ }^{5}$. Este documento no entró en los primeros setenta esquemas que habían sido planeados por la Comisión preparatoria, aunque era el único que Juan XXIII había deseado expresamente ${ }^{6}$. Por esa razón no es sorprendente que el trabajo sobre el texto se pusiera en marcha con lentitud.

El proyecto correspondió a las tareas fundamentales del Concilio. Pronto se mostró una correlación fundamental entre la meditación de la Iglesia sobre su propio ser y su apertura a las cuestiones y necesidades del mundo presente. Se vio claramente que los dos grandes temas que había propuesto el cardenal Suenens en su primer programa -"ecclesia ad intra" y "ecclesia ad extra"- se exigían y necesitaban como los focos de una elipse 7 .

Tal correlación no dejó de plantear tensiones y problemas, pero eso era lógico: había que salir de una Iglesia que aguantó incólume en las luchas y dificultades de la modernidad mediante una posición defensiva y de repliegue, pero que había perdido el encuentro viviente con la cultura contemporánea y los problemas de la sociedad. El catolicismo se había convertido en una fortaleza que conservaba en su interior la verdadera fe y gran vigor organizativo, pero se encontraba muy distante de los grandes problemas vitales controvertidos de la modernidad 8 . A casi

5Para la historia del texto, ver R. Tucci (1970) "Introducción histórica y doctrinal" en Y. Congar y M. Peuchmard, editores (1970) Vaticano II. La Iglesia en el mundo de hoy. Madrid, Taurus, II, 37-155; Ch. Moeller (21968) "Die Geschichte der Pastoralkonstitution", en Lexikon für Theologie und Kirche, Das Zweite vatikanische Konzil. Dokumente und Kommentare, v. 3, Friburgo de Brisgovia, Herder, 242-279; P. Donl, e. a. (1988) La costituzione conciliare Gaudium et Spes vent'anni dopo, Roma, Universidad Gregoriana; G. ROUTHIER (2008) "Finalizar la obra comenzada: La experiencia del cuarto período, una experiencia que ponía a prueba", en G. AlberIGo, director (2008) Historia del Concilio Vaticano II, v. 5, Salamanca, Sígueme, 59-177; P. HünermanN (2008) "Las semanas finales del Concilio": ibid., 331-434; H. J. SANDER, Theologischer Kommentar zur Pastoralkonstitution, en Herders theologischer Kommentar zum zweiten vatikanischen Konzil, Friburgo de Brisgovia, Herder, 5 vol, 2005-2006, IV, 616-700, G. ROUTHIER, (2006) L'élaboration de la doctrine sur la liberté religieuse et de l'enseignement conciliaire sur l'Église dans le monde de ce temps, en ETL 82 333-371 (350-369).

${ }^{6}$ Cf. Ch. MOeller, I. c., 245.

7lbíd., 247.

${ }^{8}$ CF. F. X. Kaufmann y A. ZINGerle, editores (1996) Vatikanum Il und Modernisierung, Paderborn, Schöningh; P. HüNERMANN, editor (1998) Das II. Vatikanum - Christlicher Glaube im Horizont globaler Modernisierung, Paderborn, Schöningh. 
todos los grandes retos entre Iglesia y sociedad, fe y cultura en la edad moderna (desde la controversia con Galileo hasta las enconadas desavenencias acerca del método crítico en la teología durante la crisis modernista) se les puede describir como situaciones de conflicto entre conservación de la identidad y capacidad de diálogo con el mundo. Así muchos debates se habían atascado: relación de la lglesia con la democracia, verificación de la libertad religiosa, papel del laico adulto en la sociedad, evaluación de la técnica y su relación con la civilización moderna, etc. Cuando no prevalecía una enemistad entre los diversos dominios, la relación quedaba determinada por la ignorancia, la indiferencia o la desconfianza. La imagen fundamental de la relación era la del dualismo entre una Iglesia que se aislaba cuidadosamente y un mundo entregado a sí mismo.

Pues bien, con este texto se buscaba una declaración fundamental que tratara el tema del encuentro entre el cristianismo y el mundo moderno sobre el fundamento de la concepción católica de la fe.

En la búsqueda de ese objetivo se presentaron varias dificultades: una historia de siglos abrumadora, la búsqueda de un lenguaje apropiado y de medios adecuados, manifestaciones de fatiga en la reelaboración continua de un gran documento; también se manifestaron entre los obispos y los teólogos actitudes nuevas de enfrentamiento. La redacción padeció por la sobrecarga de trabajo de muchos miembros de la comisión, y precisamente de los más importantes, debido a otras tareas; por esa razón la preparación no fue continua ni temporal ni materialmente. Apenas se tenían a disposición trabajos teológicos previos; no había ningún modelo estimulante y comparable proveniente de la praxis del magisterio existente. La idea de reunir en un nuevo documento la totalidad de las cuestiones actuales acerca de la orientación cristiana en el mundo de hoy, se evidenció desde el comienzo como una empresa inusitadamente arriesgada. La apertura misionera debía sustituir a una orientación hacia dentro casi narcisista. En lugar de disposiciones autoritarias se apostaba por el diálogo. En vez de reclamar derechos y privilegios propios, se ponía por delante el servicio. Un concepto abstracto de naturaleza no debía ser ya más lo dominante, sino la mirada imparcial a la realidad concreta de la persona humana y de su historia. Temas de discusión particularmente difíciles fueron la relación de la Iglesia con el progreso técnico y la referencia de la esperanza cristiana a la progresiva transformación del mundo. Resumiendo: todos estos temas se agruparon en la cuestión acerca de la reconciliación de cristianismo y modernidad. Pasaron a primer plano las cuestiones de la pobreza en el llamado "tercer mundo" y la preservación de la paz para la humanidad. Desde la Iglesia hubo de formularse de manera nueva la relación con la cultura de nuestro tiempo y las ciencias modernas. 
Aceptado el objetivo, el proceso de redacción fue por muchos motivos extraordinariamente difícil. Los problemas surgieron en primer lugar de la duda acerca de si un concilio ecuménico, que habitualmente en la tradición de la lglesia solo decide sobre contenidos de la fe propuestos urgentemente o bien sobre disciplina eclesiástica, debía ocuparse de cuestiones sociales, políticas y culturales relevantes muy debatidas, y esto necesariamente con la autoridad magisterial.

Se planteó una cuestión general: de qué fuentes debe tomar el magisterio los criterios para dar al mundo actual orientaciones vinculantes en debates tan conflictivos. Para la resolución de dichas cuestiones la ciencia teológica se mostraba insuficiente. Por una parte predominaba una consideración sobre la "naturaleza" humana relativamente abstracta y desprovista de historicidad; por otra parte, la asunción del modo de pensar bíblico exigía que se tomaran en cuenta los nuevos resultados de la exégesis; por otra, los datos empíricos de las ciencias apremiaban, colocándose en primer plano. Así surgió una cierta lucha acerca de cómo integrar las reflexiones dogmáticas y los modos empíricos de conocimiento.

Curiosamente la confrontación entre conocidos "progresistas" y "conservadores" ya no era válida en esta constelación. Los grupos de progresistas comenzaron a diferenciarse entre sí. Nuevos frentes que solo en la época después del Concilio habían de configurarse del todo fueron apareciendo lentamente.

Estas limitaciones objetivas y estructurales cristalizaron de muchas formas en el documento; luego hablaremos de ellas. Puede darse la razón a aquellos obispos participantes sustancialmente en la elaboración (por ejemplo, M. G. McGrath) que creían que hubiera sido necesario otro año más de deliberación con la perspectiva de madurar el texto, acabar de limar algunas formulaciones concretas y fortalecer la coherencia de la totalidad. En este sentido la premura de tiempo bajo la que se encontraba la elaboración obró claramente de forma perjudicial.

Sin embargo tantas dificultades no pudieron impedir que después de muchas redacciones previas se llegara a un texto global sorprendentemente bueno y matizado. En abril de 1965 apareció por primera vez el concepto de "Constitución pastoral", que fue ampliamente discutido y cuyo sentido es explicado en la importante nota 1 del proemio y que constituía una gran novedad en la tradición conciliar, sobre todo en razón de la nueva manera de tomar en serio a los destinatarios del evangelio y de ampliar su círculo a "todos los hombres" (GS 2), lo cual debe refluir sobre el estilo mismo del texto. Puede uno imaginarse el peso del trabajo casi inmenso, si se piensa solo en las 20.000 propuestas de enmiendas que debieron llevarse a cabo en la última fase de revisión del texto. 


\section{Valoración benévola de la Gaudium et spes?}

A pesar de muchas dificultades y obstáculos, el proyecto de Constitución pastoral llegó a su meta sorprendentemente bien. El resultado de la votación lo refleja: 2309 síes, 75 noes. El texto triunfó en la última fase, la prensa y el interés de una opinión pública por lo demás poco interesada sobre las cuestiones eclesiales, dirigió su atención a este último texto del Concilio.

La Gaudium et spes debe considerarse con pleno derecho como clave para interpretar todo el Vaticano II. Es el único documento que fue elaborado por el Concilio mismo y surgió totalmente de él. En él cristalizó el salto hacia delante de Juan XXIII en el discurso de apertura y se puso en práctica su idea central de impartir una enseñanza de carácter pastoral.

En este sentido algunas de sus categorías centrales como su afirmación crítica de los desarrollos socio-culturales, el reconocimiento de la justa autonomía de las realidades temporales (GS 36), la atención a la verdad propia de estas últimas, fundada teológicamente en la creación, la necesidad de saber leer y discernir los signos de los tiempos, son puntos de referencia en los que puede orientarse una teología al mismo tiempo compatible y crítica con la modernidad.

\section{I.Aspectos positivos ${ }^{10}$}

Comenzando por la metodología, nos encontramos ante un auténtico cambio de agujas: la estructura global de la Gaudium et Spes es inversa de anteriores documentos del magisterio, incluso de los del mismo Concilio. Ya desde el primer número se adopta un nuevo estilo entrando en el proceso de transmisión de la fe no a partir de la palabra de Dios o del evangelio, sino partiendo de los destinatarios, orientando la escucha hacia lo que les habita en lo más profundo de sí mismos: todo lo que es verdaderamente humano suscita la capacidad de escucha de los discípulos de Jesús (GS 1). Se sirve por tanto de una metodología inductiva, reconociendo que a la Iglesia no solo le corresponde una mirada desde dentro de sí a partir de la cual considera el mundo, sino también una mirada desde fuera,

\footnotetext{
9 El texto de la Constitución Gaudium et spes se supone conocido; véase F. GIL Helúí, editor (2003) Concilii Vaticani II Synopsis: Gaudium et Spes = Studi sul Vaticano II, v. 4, Ciudad del Vaticano.
}

10K. Lehmann (2005) "Christliche Weltverantwortung zwischen Getto und Anpassung. Vierzig Jahre Pastoralkonstitution "Gaudium et Spes" ": ThPQ 153,3, 297-310 (301). 
a partir de la cual capta su propio interior. Aquí se produce el desplazamiento: se afrontan los problemas no partiendo de principios eternos, sino de la conciencia que tiene la humanidad contemporánea de dichos problemas. El uso de ese método es una novedad de importancia excepcional para el catolicismo: el texto está organizado según el esquema inductivo de la pedagogía de la Acción Católica (Ver-juzgar-actuar), que fue introducido como esquema estructurante en la primavera de $1965^{11}$.

Detengámonos un momento en este aspecto de la metodología. El último número de la exposición preliminar (GS 10) es de gran importancia porque establece el vínculo entre este diagnóstico (ver) y la posición de la fe y de la lglesia que la transmite (juzgar). Esta vinculación reinventa el gran modelo agustiniano del "corazón inquieto", de las cosas exteriores hacia las interiores, y a través de lo inferior, hacia las cosas superiores (ab exterioribus ad interiora, ab inferioribus ad superiora $)^{12}$. La lucha por escoger y renunciar se hace más dramática todavía en razón de la división interna del hombre, causa de las "discordias" en el seno de la sociedad. Como san Agustín, la exposición preliminar describe esta división con ayuda de $\mathrm{Rm}$ 7, 14 ss. Queda por establecer el vínculo entre el diagnóstico del mundo contemporáneo, el juicio de la fe y la manera de proceder (el actuar) según la Constitución pastoral. Dado que el documento no tiene la pretensión de abordar todos los problemas que se plantean hoy día (GS 46, 1) y es consciente del carácter provisional de su acercamiento a los más urgentes, que trata en dicha segunda parte, es de la mayor importancia pedagógica que los receptores del texto tengan un método, un modus procedendi para abordar las nuevas situaciones que se presentarán ${ }^{13}$. Tal modus procedendi tiene dos vertientes, una más afectiva y otra más intelectual. La primera proviene de ese eje del documento conciliar que consiste en el acercamiento al mundo contemporáneo a través de la capacidad de escucha de los cristianos, tal como hemos recordado. La vertiente intelectual se resume en el discernimiento-juicio que se convierte en "la ley de toda proclamación adaptada de la palabra revelada" (GS 44). La Gaudium et Spes intenta hacer de este modus procedendi el primer impulso del desarrollo de una conciencia hermenéutica que se vaya adaptando a la situación contemporánea del mundo y de la lglesia.

${ }^{11} \mathrm{CF}$ H. J. SANDER, Theologischer Kommentar, o. c. IV, 638 s, 644.

${ }^{12}$ Enarrationes in Psalmos 145,5, en J.P.MIGNE, Patrología latina, 37, col. 1887.

${ }^{13}$ Cf. Acta Synodalia concilii oecumenici Vaticani II, Ciudad del Vaticano 1970, Editora Vaticana, 4/6, 565. 
De esta metodología inductiva se deriva una conclusión importante: la nueva forma de situarse ante el mundo de la Iglesia conlleva la aceptación de una continua reinterpretación de sí misma y de su mensaje a partir de la realidad cambiante de la historia. Trataremos de esta decisiva cuestión más adelante.

Otro aspecto importante referente a la metodología es la utilización del lenguaje del diálogo. Ya desde la introducción, que habla de la situación del hombre en el mundo actual, la percepción crítica de la misma no se propone con el objetivo de la confrontación y la condena, sino bajo el signo del diálogo, palabra "princeps" del concilio. El análisis de la situación quiere ser plenamente justo y se apoya para ello en los resultados científicos especializados, pero tiene al mismo tiempo una intención religiosa, a saber, descubrir los signos de los tiempos (n. 4), que son verdaderos signos de la presencia o de la intención de Dios en nuestra época (n. 11$)^{14}$.

Hablamos del lenguaje del diálogo. En efecto, los redactores en la Relatio ${ }^{15}$ ex- $^{-}$ plicativa del texto apelan al discurso de apertura de Juan XXIII y a sus encíclicas, donde el papa estableció el lenguaje del diálogo con el mundo, afirmando que el mundo no es impermeable a la palabra de Jesús y puede ser orientado hacia El. Este texto ha querido ser más evangélico que técnico, utilizando palabras simples como lo son las palabras evangélicas. Ha querido ser más dinámico que abstracto y teórico, para estar cercano a los problemas humanos a los que se ha dado por objetivo abordar. En fin, se ha esforzado al máximo en ser fiel a la verdad de la fe y al mismo tiempo a la realidad de la vida humana. En el trasfondo de estas indicaciones de la Relatio se perfila la cuestión de la forma pastoral de la doctrina y del posicionamiento de ella en la relación kerigmática de la lglesia con toda persona humana.

El lenguaje del diálogo afecta a la forma de presentar el contenido. Del discurso anterior, únicamente fundado sobre la ley natural y leyes morales positivas así como sobre la sumisión que ellas exigen, se pasa a un discurso parenético de inspiración sapiencial y diferenciado según las materias. Rahner ya anotó esta mutación, llamando la atención sobre los límites de toda ley general cuando se trata de tener en cuenta la situación concreta de la persona, utilizando entonces la terminología del consejo que apela sobre todo a la capacidad de discernimiento

${ }^{14} \mathrm{Cf}$. H. J. Pottmeyer (1996) "Modernisierung in der katholischen Kirche am Beispiel der Kirchenkonzeption des I. und II. Vatikanischen Konzils": F. X. KaufMANN y A. ZINGERLE, editores (1996), Vatikanum II. und Modernisierung, Paderborn, Schonningh, 131-146 (139).

${ }^{15}$ Acta Synodalia concilii oecumenici Vaticani II, Ciudad del Vaticano 1970, Editora Vaticana, 4/1, 557. 
de los individuos y de los grupos ${ }^{16}$. Esto representa sin duda un cambio de estilo importante introducido por la Constitución pastoral, puesto que se refiere a la posición de la Iglesia en el discernimiento moral del actuar y a la imagen que ella da de sí misma en la sociedad.

Después del Concilio se ha dicho que los padres conciliares no se daban cuenta del cambio de metodología, de que practicaban teología de una manera esencialmente distinta a lo que era corriente en la teología escolástica. La afirmación es plausible, al menos respecto a un buen número de obispos. Pero eso no equivale a ningún reproche. Quien actúa públicamente en coherencia consigo mismo, no siempre reflexiona sobre los presupuestos metodológicos que están implícitos en su acción.

En cuanto al contenido, probablemente el aspecto más innovador de la Constitución es el reconocimiento del valor positivo desde el punto de vista de la fe del proceso de secularización fundado sobre la autonomía relativa de la persona humana y de las realidades terrestres con respecto a la religión y a la Iglesia. La asunción de responsabilidades históricas por parte del ser humano es plenamente legítima y constituye un progreso. El Concilio acepta la característica más relevante del mundo moderno y de su cultura en relación con la lglesia: la laicidad. Las realidades temporales aparecen en su singularidad y con sus propias leyes. ${ }^{17}$ He aquí un principio unificador de la enseñanza conciliar. Desde este punto de vista la Constitución pastoral ha de valorarse como el intento de comprender la ambivalencia de la modernidad. La exposición preliminar y el capítulo II de la $2^{a}$ parte dan una visión global de esa "edad nueva" de la historia de la humanidad, vivida bajo el signo de la mundialización. El eje del diagnóstico, sobre el que se vuelve en varias ocasiones, es el "antropocentrismo" lo que hace que a fin de cuentas el hombre no está más que frente a sí mismo (GS 2;4).

El hecho de que el Concilio no solo firmó una constitución sobre el misterio de la lglesia, sino que añadió otra sobre la lglesia "in mundo huius temporis"(GS, nota 1) es significativo y nuevo porque con ello se expresa la convicción de q-ue para la lglesia es esencial estar en el mundo. La lglesia se experimenta estrechamente vinculada con la humanidad y su historia e injertada en ella (GS 1; 3). Es característico el subrayado de la mutua implicación de la realidad social e histórica y su dimensión trascendente, lo cual advirtámoslo bien- es válido

\footnotetext{
16K. RAHNER (1968) "Reflexiones sobre la problemática teológica de una constitución pastoral": La lglesia en el mundo actual. Constitución "Gaudium et Spes», Bilbao, Desclée de Brouwer, 19-43.
}

17K. LEHMANN, Hermeneutik für einen künftigen Umgang mit dem Konzil, en: G. WASSILOVSKY (editor), Zweites Vatikanum -Vergessene Anstösse, gegenwärtige Fortschreibungen, Friburgo Br. (Herder) 2004, 71-89 (80-81). 
tanto para el mundo como para la Iglesia. Los padres conciliares estaban convencidos de que la honrada confrontación con los problemas del mundo, así como la libre aceptación y afirmación de los nuevos conocimientos de la humanidad llevarían a una nueva posición en relación con la plausibilidad de la lglesia y podrían enmarcar un nuevo proceso abierto, establecido sobre el consenso. En resumen: se superó ampliamente el enfrentamiento dualista entre la Iglesia y el mundo.

La actitud que aquí se pide presupone una apertura de la Iglesia al mundo, más aun, una verdadera y propia consciencia de que la Iglesia no se contrapone al mundo ni puede estar separada del mundo, sino que está en relación con el mundo, en una relación de co-pertenencia recíproca entre la Iglesia y el mundo: una co-pertenencia que deviene compartir solidario de todo cuanto en el mundo hay de verdadero, de justo, de bueno y de bello.

En estas páginas la Iglesia mira a las grandes transformaciones presentes con una actitud positiva, participante, apasionada y en ellas se advierte todo el impulso de una nueva fase que se ha abierto en la historia de la Iglesia. Es la fase de una atención que la Iglesia, en fidelidad a su Señor, cuya misión en la historia continúa, dirige a la humanidad entera, atención que se hace testimonio de la verdad y servicio desinteresado a la persona humana.

La Iglesia comprendió que la historia concreta de las personas en el mundo, su vida cotidiana y sus luchas son el lugar teológico en el que se da la salvación y tomó conciencia de que ella tenía que comprenderse como parte integrante de las iniciativas, los esfuerzos y las luchas en favor de la justicia social, de la paz del mundo, contra el subdesarrollo y el colonialismo. El Espíritu de Dios estaba presente ahí, en esos esfuerzos, precisamente donde la lglesia muchas veces estaba ausente. La historia y la sociedad ${ }^{18}$ fueron comprendidas como el lugar teológico en el que estaba en juego la realidad del reino de Dios. El reino es de Dios, pero es preciso que la historia y la sociedad humana se transformen para que él acontezca. La I glesia se entendió a sí misma como servicio a la humanidad por causa y en vista del reino de Dios. Su actividad pastoral y misionera nacen de esta comprensión teológica fundamental ${ }^{19}$. Es esta una especie de revolución copernicana que se presenta a la estupefacta consideración de todos desde el famoso incipit de la ${ }^{18}$ Es sintomático el título de la obra de J. B. METz (1979) La fe en la historia y en la sociedad, Madrid,
Cristiandad (original de 1974).

19 A. Da Silva Moreira (2006) O legado do Concilio e os sinais do nosso tempo, en: Id., A primavera interrumpida. O projeto Vaticano II num impasse, servicioskoinonia.org/libros digitales II, 83-90 (83-88). 
Constitución; es el soplo renovador que atraviesa todas sus páginas ${ }^{20}$.

La Constitución pastoral obedece a una estructura que se apoya sobre una percepción precisa de la cultura moderna y su diferenciación interna y sobre una redefinición del papel profético de la Iglesia en el seno de esta cultura. El texto ofrece un "reencuadramiento" de la doctrina clásica acerca de la persona humana, la sociedad y la acción humana en el mundo a partir de una relectura de la economía de la salvación según el pensamiento bíblico. En este punto se une al eje de pensamiento de la Dei verbum, aunque inaugurando al mismo tiempo otro tipo de lectura interpretativa que es la de los tiempos modernos, lectura comprometida bajo el título emblemático del discernimiento de los signos de los tiempos.

En conclusión: el Concilio hizo que la Iglesia cambiase radicalmente la concepción que tenía de sí misma. La desconfianza y el rechazo de los movimientos sociales y políticos dejaron de determinar la postura de la lglesia en relación con el mundo. La Iglesia conciliar quiso comprometerse con radicalidad en el seguimiento de Jesús y no desanimarse ante los desafíos ni acomodarse ante las situaciones de injusticia y sufrimiento existentes, buscando con los hombres y mujeres de buena voluntad soluciones para los graves problemas de la humanidad. Quiso colocar en el centro de sus preocupaciones no a sí misma sino a todo aquello que es verdaderamente humano, dialogando con todos los que luchan por el bien y buscan la verdad. ${ }^{21}$

\subsection{Limitaciones y debilidades}

La valoración positiva fundamental de la Constitución pastoral no impide que se muestren sus límites. Estos pueden suponerse a través del proceso ya explicado de su gestación.

\footnotetext{
20 Desde este punto de vista la lglesia atravesó un umbral decisivo en el momento en que dio por vez primera un sentido propiamente teológico a la autonomía de la historia. En realidad este umbral se puede situar inicialmente antes de la Gaudium et spes, en el discurso de apertura del Concilio, Gaudet mater Ecclesia, en el que Juan XXIII propuso una lectura sapiencial de la historia humana y dio pruebas de una atención nueva a la capacidad de aprendizaje de los humanos. Se vuelve a encontrar en la "Exposición preliminar" de la Gaudium et spes sobre la condición humana en el mundo de hoy, donde sin utilizar el término "modernidad", se habla de "una edad nueva de la historia del género humano" (GS 4) y luego en los célebres párrafos acerca de la autonomía de las realidades terrestres.
}

${ }^{21}$ A. Da Silva Moreira, O legado do Concilio..., ibíd. 
No era fácil ganar la adhesión de los obispos en favor de una deliberación exhaustiva acerca de numerosos problemas mudables, vinculados a la época y condicionados histórica y sociológicamente ${ }^{22}$. La amplitud del documento probablemente superaba los límites posibles desde el punto de vista de la técnica del trabajo para un grupo de dos mil quinientos obispos.

En primer lugar hay que anotar el insuficiente entrelazamiento con los otros documentos conciliares. Extraña que apenas se hable de la dimensión de oración y celebración: no existe una seria conexión con la Constitución sobre la liturgia (solo se encuentra una referencia a Sacrosanctum Concilium). La correlación con la Constitución sobre la Iglesia Lumen gentium aparece extraordinariamente débil. La distinción, de la que ya hemos hablado, entre una Iglesia "hacia dentro" y una Iglesia "hacia fuera", históricamente comprensible, pero objetivamente cuestionable, hubiera podido ser positivamente superada mediante un engranaje más fuerte precisamente con la Constitución sobre la Iglesia. Más grave resulta que dos documentos del Concilio de la más alta significación teológica, a saber, la Constitución sobre la divina revelación y el Decreto sobre el ecumenismo ni se citan. Si las orientaciones de sus conclusiones se hubieran aprovechado, hubieran sido más precisos los presupuestos del envío de la lglesia al mundo y también las exigencias de su responsabilidad en él. Pues solo una Iglesia renovada y fortalecida desde su interior puede atreverse a asumir una misión intensiva en el mundo. A partir del modelo "revelación e historia", tal como se explica en la Constitución Dei Verbum se hubieran podido comprender muchas afirmaciones sobre la unidad de la historia del mundo y de la historia de la salvación en la Gaudium et spes.

Aquí tocamos un punto importante: los límites de la estructura hermenéutica de la Constitución pastoral. En efecto, la historia de su redacción nos descubre que no aparece más que en algunos momentos la forma relacional del proceso de interpretación del evangelio, el llamado "círculo hermenéutico". La afirmación de principio de que la predicación de la palabra revelada "acomodada" a las lenguas y culturas de los pueblos es la ley de toda evangelización (GS 44, 2) y la de que Dios se revela según la cultura propia de las diversas épocas (GS 58, 1 ) fueron introducidas a última hora, el 2.12.1965, sin poder refluir sobre el resto de la Constitución. Se trata, según la expresión de K. Rahner ${ }^{23}$, de perchas donde colgar elaboraciones ulteriores. Quiere decir K. Rahner que la tarea de escrutar los signos de los tiempos con vistas a una evangelización contextualizada apela a una metodología de análisis y unos

${ }^{22}$ Cf K. RAHNER, Reflexiones sobre la problemática teológica..., o. c., 20-21, 38-43

${ }^{23}$ Carta del 27-IV-1964 a H. Vorgrimmler, en: H. VORGRIMMLER (1985) Karl Rahnerverstehen. Eine Einführung in sein Leben und Denken, Friburgo de Brisgovia, Herder, 218. 
presupuestos en el campo de la teología fundamental que no han sido reflexionados como tales $y$, por tanto, no se pudieron asumir en la Constitución pastoral. Como ya reconocía el profesor J. Ratzinger ${ }^{24}$, no disponemos todavía de reglas para una hermenéutica kerygmática; nos vemos obligados a atenernos solamente a las exigencias de la exégesis histórica, la cual, por ahora, no nos ayuda en la actualización de la Escritura. Pero precisamente el texto de la Gaudium et spes trata del problema de la actualización de lo que es ser cristiano. Es este un problema que ha quedado pendiente para la Iglesia de nuestro tiempo.

En segundo lugar, no puede negarse que en el texto se expresa una cierta euforia de nuevo comienzo, de la que también hay algún rastro en los discursos de apertura de Pablo VI en los correspondientes períodos de sesiones, y que también muchas afirmaciones están selladas por una credibilidad en el progreso un tanto ingenua ${ }^{25}$. Era signo de la nueva esperanza que no deberíamos rechazar sin más; consistía en una especie de tributo al espíritu de la época, como puede verse claramente desde la distancia que proporcionan los cincuenta años pasados desde entonces.

Hay que reconocer que en aquel momento el episcopado fue bastante optimista en la apreciación de la situación contemporánea y confiado en el futuro. Dio la impresión de que pensaba que el sistema de la sociedad del bienestar podría lograr la solución a los problemas sociales del mundo. No previó -no podía prever- el retorno triunfal del liberalismo en la década de los setenta. Ciertamente nadie había previsto esa evolución, pero el Concilio podía haber sido más crítico respecto del sistema capitalista como tal ${ }^{26}$.

Aunque el Vaticano II quiso que la Iglesia se abriese al mundo, sintonizase con los acontecimientos de su tiempo, ya marchaba con retraso para responder a su propio contexto, porque recibía un legado de siglos de conflictos de la lglesia con el mundo moderno. Intentaba hacer las paces con la modernidad, pero ésta ya se encontraba marcada por profundas crisis y apuntaba al surgimiento de una posmodernidad desencantada con las promesas incumplidas de la modernidad.

${ }^{24} \mathrm{LThK}^{2}$, Das zweite vatikanische Konzil. Dokumente und Kommentare, Friburgo de Brisgovia, 1968, Herder, $3,313 \mathrm{~s}$.

${ }^{25}$ Como ejemplo de denuncia de esta ingenuidad u optimismo de la exposición preliminar de la Constitución, puede verse J. RATZINGER (1985) Teoría de los principios teológicos. Materiales para una teología fundamental, Barcelona, Herder, 456-459, así como en J. RATZINGER y V. MESSORI (1985) Informe sobre la fe, Madrid, BAC, 31-32.

26 J.Y. Calvez (2003) Los silencios de la doctrina social católica, México, Instituto Mexicano de Doctrina Social Cristiana (París 1999). 
Ya antes de finalizar el Concilio se planteó una dura crítica en el interior mismo de los expertos del propio Concilio. La crítica se dirigía sobre todo a la toma de posición ante el progreso técnico y en general ante la civilización moderna. Se descubría en el texto una identificación cándida del progreso técnico con el "progreso cristiano". La configuración del mundo por el hombre y la espera del Reino se vinculaban estrechamente entre sí. También se achacaba al texto que introducía un componente teológico discutible en la interpretación del progreso técnico vinculándolo estrechamente con él: a saber, el proceso creciente de humanización del mundo parece corresponderse con el desarrollo histórico del Cristo cósmico. Consecuentemente en las afirmaciones acerca de la relación entre bien y salvación, progreso y vida eterna, historia y eternidad, inmanencia y trascendencia eran predominantes las afirmaciones de convergencia, mientras que los aspectos de la diferencia más bien pasaron a segundo término. No se logró llamar por su nombre a los lados oscuros del progreso y a la permanente ambivalencia de muchos desarrollos. Esta característica es comprensible desde la intención de la Constitución pastoral, pues se quiso desmontar el resentimiento contra la civilización técnica. Sin embargo es claro que faltó la fuerza para decir este sí al mundo de tal forma que también se retuviera sin prejuicios y sobriamente tanto la ambivalencia como el retroceso en el desarrollo.

Una reflexión más profunda sobre la fuerza propia de la redención cristiana y del misterio de Cristo hubiera preservado de una conciliación algo apresurada entre cristianismo y modernidad y hubiera podido evitar una transfiguración de lo técnico que en alguna ocasión aparece demasiado luminosa. Precisamente los observadores de las Iglesias no católicas advirtieron claramente de tales peligros ${ }^{27}$.

Siendo cierto todo lo dicho, no es menos cierto que la Constitución debe juzgarse con mayor justicia de lo que sucede en ocasiones. La modernidad no queda bautizada ingenuamente en la exposición preliminar y menos todavía se desconocen los efectos perversos de esta nueva situación, entre ellos, principalmente de la incertidumbre del ser humano en relación consigo mismo y de la crisis de orientación que resulta de ese antropocentrismo (GS 4,3). El texto propone a continuación (GS $4,4)$ una serie de paradojas provocadas por el problema de la orientación de la modernidad; se les vuelve a encontrar en GS 8 bajo el título de "Los desequilibrios en el mundo actual", cuyas raíces últimas están situadas en el corazón humano (GS 10) y en GS 56, 1 que habla de las "múltiples antinomias". Resumiendo: el texto insiste tanto sobre la ambigüedad de la situación del hombre contemporáneo como sobre su apertura radical. En el fondo la alternativa que se presenta al fin del $n^{\circ} 9$ así como la tensión entre la esperanza y la angustia atraviesan toda la

${ }^{27} \mathrm{Cf}$, por ejemplo, E. ScHuINK (1966) Nach dem Konzil, Munich-Hamburgo, Siebenstern, 135-164. 
historia de estos cincuenta años de recepción del Vaticano Il: según el polo que se subraye en los desequilibrios y antinomias del mundo contemporáneo, la esperanza - la angustia, el carácter situado de los problemas o las cuestiones eternas, etc., se llega a una interpretación diferente de los datos y a una visión distinta de la presencia del evangelio y de la lglesia en la sociedad. La estructura del "sí... pero" con sus posibles inversiones, que fue característica de la recepción del Vaticano II en el pontificado de Juan Pablo II, es una manifestación de todo ello. Una prueba más de que las dificultades de la recepción no provienen de una hermenéutica deficiente, sino que se enraízan en última instancia en el carácter problemático del mundo contemporáneo que se refleja en el diagnóstico muy lúcido que hace de él la exposición preliminar.

La Constitución manifiesta claramente la fragilidad de la existencia humana, la ambivalencia del "progreso" y la fuerza del pecado más de lo que muchos teólogos recuerdan, quizá porque a menudo argumentan a partir de fases previas del texto. En el texto final hay bastantes frenos ante una interpretación en el sentido de una fe optimista en el progreso; el conocimiento de su lado oscuro y de la permanente ambigüedad de muchos avances está bien presente. Si nos fijamos en muchos de los problemas tratados como, por ejemplo, la relación entre la salvación y el bienestar humano, el progreso técnico y la fe, la Gaudium et spes es mucho más matizada de lo que algunos de sus críticos afirman. Hubo teólogos conciliares y ciertos obispos en la etapa final del Concilio que no percibieron correctamente las modificaciones de la última redacción. El texto aprobado tiene en cuenta plenamente la multiplicidad de experiencias de mundo, también desde la perspectiva de la fuerza del pecado en el mundo.

En resumen, la Gaudium etspes en muchas cosas no muestra una solución satisfactoria que deba mantenerse sin más para siempre. Hoy no se puede leer ingenuamente un texto de 1965, sino que se debe intentar comprenderlo en su amplia intención y estructura a través de la historia de sus efectos ${ }^{28}$.

\subsection{Algunas cuestiones pendientes}

La Constitución pastoral planteó algunas tareas de carácter metodológico que solo fueron desarrolladas a medias: la criteriología para con los "signos de los tiempos", el papel de la experiencia y del empirismo en la actuación de la lglesia,

${ }^{28} \mathrm{Cf}$ A. Losinger (1989) "lusta autonomia". Studien zu einem Schlüsselbegriff des II.Vatikanischen Konzils, Paderborn, Schöningh. 
el método inductivo, la cuestión de las formas de pensamiento, la problemática de una "constitución pastoral", etc.

En estas y otras muchas cuestiones la Iglesia de hoy tiene una tarea permanente que aun no se ha cumplido. Incluso se puede con buenas razones defender la tesis de que todavía no ha empezado la recepción real de la Constitución Pastoral. Una larga lista de conocimientos de carácter metodológico y de problemas han sido en cierto modo marcados oficialmente como tarea, porque no fueron resueltos satisfactoriamente por la Constitución.

Esto vale ante todo para la comprensión de los "signos de los tiempos" y para los criterios de juicio sobre ellos. Juan XXIII, al usar esa palabra clave, expresó que para la Iglesia no es decisiva solo una determinada época, sino que cada tiempo debe investigar a la luz del evangelio acerca de las huellas del Espíritu de Dios. Ya tal formulación muestra que la expresión equívoca "signos de los tiempos" solo puede hacerse fructífera para la fe y la Iglesia mediante el ensayo en el discernimiento de espíritus.

Otro importante cambio de horizonte es el hecho de que la Constitución pastoral, aunque metodológicamente se plantea "desde abajo", pone en juego experiencias que no se limitan solo a la realidad verificable. Con ello se planteaba la tarea, que humanamente no podía resolver al Concilio, de conjugar modos de conocimiento de las ciencias sociales con datos normativos fundamentales de la fe cristiana. Aunque ese propósito no se logró suficientemente, sin embargo con ello se aseguró un requisito metodológico impagable para la reflexión teológica pastoral.

Por fin, se avanzó poco en la tarea de integrar un pensamiento teológico renovado, las formas bíblicas de pensamiento y los conocimientos científicos logrados empíricamente. Pese a todas esas tareas pendientes, la carga profética de la Gaudium et spes no ha disminuido. Pensemos en las características del tiempo que estamos viviendo, o mejor, en las actitudes más profundas que habitan en el corazón de la humanidad de hoy. Nuestro tiempo es semejante en muchos aspectos y situaciones a aquel en el que se celebró el Concilio. Léase la alocución pronunciada por Pablo VI durante la sesión pública con que se clausuró el Concilio y se verá cómo en esa descripción se encuentran -aunque quizá con manifestaciones en parte diversas de entonces- rasgos que continúan caracterizando nuestra época ${ }^{29}$.

29 PABLO VI, Alocución pronunciada en la Basilica Vaticana durante la sesión pública con la que clausuró el Concilio, 7-XII-1965, n 6. Concilio Vaticano II. Constituciones. Decretos. Declaraciones, Madrid, Católica (BAC) $1965,815$. 
Precisamente en un mundo como el nuestro, en el que muchos, privados del horizonte totalizador de las ideologías, quisieran reducir todo al fragmento, al instante, a la dignidad de ser humanos, solo humanos y nada más que humanos, y en el cual bastantes creyentes están tentados de contraponer a ese nihilismo posmoderno un cristianismo de certezas fáciles, precisamente en este tiempo aparecen con nitidez la importancia y la actualidad de una perspectiva e interpretación unitaria y unificante, eminentemente religiosa. La relectura de la Constitución se convierte en un punto de referencia para el futuro y un momento precioso para reencontrar de modo convincente algunas líneas para la misión de la Iglesia en el mundo de hoy.

Para concluir este epígrafe volvamos a afirmar que la Gaudium et Spes, el último documento aprobado antes de cerrarse las puertas del Concilio, es una ventana abierta de la Iglesia al mundo. Aquí encontramos de una forma paradigmática aquella actitud de interés, de atención, de amor al mundo que ha caracterizado todo el Concilio.

Fue precisamente esta la gran novedad solemnemente inaugurada por el Concilio y en particular por la Constitución pastoral. Una novedad significativa sobre todo si se tienen en cuenta las distancias y fracturas entre la Iglesia y la sociedad profana mantenidas en los últimos siglos. La apertura al mundo no era una tolerancia para con el relativismo, con la moda cultural o con el llamado "espíritu de la época", sino la actitud sugerida por la misión salvadora esencial a la lglesia. Actitud nueva que emerge de modo sintomático en la valentía con la que Gaudium et Spes ha afrontado los múltiples problemas que desde hacía mucho tiempo seguían ardiendo bajo las cenizas y que encuentran una consideración amplia y articulada sobre todo en las páginas de la segunda parte. ${ }^{30}$

\section{Recepción de la Constitución en el posconcilio}

La distancia histórica que nos separa de la Gaudium et spes se refleja de manera directa en los contextos globales y locales que fueron presupuestos por el texto. La novedad de la situación presente es la de una mutación cultural sin precedentes. Hemos de preguntarnos si los cambios culturales que se han producido desde el final del Concilio no llegan hasta cuestionar la estructura hermenéutica de la Constitución, precisamente en razón de su condición inacabada. No hay duda

30 D. Tettamanzi (2005) La missione della Chiesa nel mondo di oggi. Seguendo la bussola della Gaudium et spes, www.vivailconcilio.it/Saggi teologici $n^{\circ} 50,1$. 
alguna de que el escenario de nuestra sociedad ha evolucionado rápidamente en estos cincuenta años, que muchas cosas han cambiado desde entonces, que en el entretiempo han surgido otras problemáticas y se han presentado nuevos desafíos.

Se trata sobre todo de un cambio de atmósfera. Mientras que los años sesenta estaban atravesados de una voluntad de cambiar el mundo, hoy el horizonte de las grandes ideologías se ha derrumbado y se hacen presentes los escenarios de confrontaciones y de colisiones amenazantes con las nuevas culturas y las religiones. Ha cambiado también el sentimiento del hombre moderno: ya no está impulsado por una visión ideal del mundo, sino que está a la búsqueda de un sentido de la vida replegado sobre el fragmento, sobre las emociones, sobre los sentimientos y sobre las experiencias que aseguran una buena calidad de la existencia.

Aunque muchos desafíos surgidos en el posconcilio ya se anunciaban antes del Concilio, a partir sobre todo del año 1968 se produjo un cambio de clima espiritual que significó la irrupción de forma aparatosa de la creciente secularización.

Las ideologías en general, las religiones y sus tradiciones, así como el significado de toda institución, no solo de las religiosas, quebró de forma tremenda.

En este crucial momento histórico faltó desde muchos puntos de vista en la comunidad cristiana una transmisión adecuada de la Constitución pastoral y, sobre todo, un análisis diferenciado de las cuestiones fundamentales de carácter teológico, espiritual y pastoral en ella compendiadas. Hablando en general, incluso hasta el presente se han descuidado demasiado los medios formativos de acompañamiento en la iniciación a ese documento conciliar y a su recepción.

Puede uno preguntarse si ha habido fases diversas claras en el proceso de recepción de estos cincuenta años. No es tan fácil responder, porque los campos de problemas particulares y los acentos regionales son muy diversos. Se entiendan como se entiendan cada una de esas fases, la recepción ha constituido una ocasión para que se dilate universalmente la entera realidad de la experiencia conciliar. Ahí ha estado en juego la capacidad del cristianismo para discernir la fuerza que impulsó al Concilio, separando la sustancia viva de los accidentes muertos. No ha sido un discernimiento fácil ni rápido y, sobre todo, ha sido un discernimiento exigente que ha implicado disponibilidad y compromiso en la conversión y en la búsqueda. 


\section{I. Se abre una crisis en la relación de la Iglesia con el mundo}

Es un hecho constatable que, a pesar de la Gaudium et spes, se produjo una crisis en la apertura de la Iglesia al mundo. Se había comenzado a practicar un diálogo responsable y una solidaridad realmente beneficiosa, aunque crítica. Pero pronto se pasó a veces de la necesaria apertura a una acomodación desacertada. En algunos aspectos hubo una entrega ingenua al mundo, sin calcular la fuerza atenazadora del abrazo del oso. Una cierta línea de interpretación "progresista" desacopló la Constitución pastoral de los otros documentos conciliares que intentan una nueva interpretación de la identidad de la fe cristiana, descuidando en el diálogo con el mundo la diferencia (ique no la separación!) entre el mundo secular y la fe.

Pero esto no debe cargarse en cuenta a la propia Constitución: un texto solo no crea tales cambios a partir de sí mismo. Una recepción seguramente unilateral de la Constitución -no sin conexión con sus propias zonas de sombra- no puede fundamentar esa crisis de apertura al mundo. Sucedió que durante el proceso posconciliar se manifestó todo lo que estaba represado en la Iglesia. En el mundo moderno se habían desarrollado fermentos de cultura y de vida social que ahora penetraron como un torbellino por las puertas abiertas de la lglesia. Ella estaba de tal forma dispuesta para la defensa y la resistencia que prácticamente fue incapaz de apertura al mundo con el necesario discernimiento de espíritus. El gueto reclamó su precio: en el diálogo con el mundo moderno había pocas fuerzas vivas auténticas. Así de la necesaria apertura resultó no pocas veces una asimilación no buscada.

Ciertamente hay que preguntarse por el conjunto de los motivos. Análogamente a como la situación del "mundo de este tiempo" influyó en el contenido de la Constitución pastoral, su recepción fue influida por el contexto social en que se desarrolló. Una causa esencial de la difícil recepción es ante todo la ruptura extraordinariamente decisiva de los años 1968 a 1974, a la que nos hemos referido antes. No era solo crítica y destrucción, sino que detrás de esas formas de rechazo y negación en la sociedad establecida, se encontraba un amplio haz de necesidades: salida de toda servidumbre para ganar una libertad sin límites, liberación del peso de la historia y de la autoridad en favor de la búsqueda de una identidad sin mermas, aniquilación de las antiguas estructuras de dominio para lograr una existencia en proceso de emancipación constante. El "mundo" se había convertido de repente en algo muy distinto. Ya no tenía el brillo del progreso técnico imparable y de una libertad siempre creciente, sino que se experimentó como un conjunto de relaciones a transformar, cuya verdad y justicia ahora se impugna apasionadamente en protesta militante. 
La Iglesia misma tuvo que experimentar muy rápidamente que con ella no se procedería de distinta manera que con las demás instituciones establecidas. Y lo experimentó más desde dentro que desde fuera. Si con la aprobación de la Gaudium et spes se pudo tener la impresión de que con dicho documento se abría en ayuda del mundo una Iglesia casi eximida de sus responsabilidades históricas, ahora hubo en su interior una resonancia totalmente inesperada de la gran ruptura cultural. No es casual que precisamente en esta época algunos teólogos que habían configurado el Concilio pusieran precisamente la palabra "crisis" o equivalentes como título de sus libros ${ }^{31}$.

El desarrollo posterior es conocido. A causa de una rígida polarización de múltiples formas la Iglesia pierde en muchos países su fuerza para la responsabilidad ante el mundo. Entre tanto en esos años decisivos de transformaciones sociales y culturales la Iglesia estaba fuertemente orientada hacia dentro y -al menos en occidente- ocupada de forma extraordinariamente intensiva consigo misma: con la reforma litúrgica, la renovación de las estructuras y ministerios en su propio ámbito, la puesta en marcha de los consejos, etc. Así perdió una vez más oportunidades para su tarea en el mundo ${ }^{32}$. El conflicto todavía se agudizó mundialmente en el año 1968 con motivo de la encíclica Humanae vitae.

\title{
4.2. Cambios en la concepción teológica del mundo
}

Los cambios en la teología del mundo que se han dado durante estos cincuenta años no siempre están en conexión directa con la problemática suscitada por la Gaudium et spes pero en última instancia no son comprensibles sin la ruptura conciliar.

Por una parte, se ha radicalizado la autonomía relativa de lo temporal, pasando a ser considerada como absoluta. A veces incluso se llega a afirmar la total emancipación del "mundo mundano", lo que conduce a una yuxtaposición indiferente de Iglesia y mundo.

\footnotetext{
${ }^{31}$ Por ejemplo, H. de LUBAC (1969) L'Église dans la crise actuelle, París, Cerf; J.Y. Congar (1972) Entre borrascas: la Iglesia hoy afronta su futuro, Estella (Navarra), Verbo Divino.
}

\begin{abstract}
${ }^{32}$ Esto es válido al menos para el catolicismo llamado occidental. Dar un juicio global es difícil, como lo muestra la evolución totalmente diferente en los países de Latinoamérica donde a causa del empuje del Concilio y particularmente en relación con la Gaudium et spes se realizó un cambio peculiar. Quizá es el cambio de las Iglesias latinoamericanas el acontecimiento más durable que ha tomado su punto de partida de la Constitución.
\end{abstract}


Por otra parte, se ha realzado la dimensión de futuro de la historia. El futuro es el constitutivo verdadero de la historia. El término "mundo" deviene una dimensión que se caracteriza por el "proceso histórico de hominización", el teatro de la actuación del hombre, actuación que le libera de la historia anterior. El mundo se identifica con la historia humana desde la perspectiva de la emancipación o la revolución.

A pesar de lo cual -he aquí otra característica- la orientación total al futuro es corregida por la figura de la "memoria" que se apoya en aquellas tradiciones que hasta ahora fueron oprimidas y que evocan lo peligroso y provocador de las esperanzas hasta ahora no cumplidas. Así, con la mirada hacia atrás, se intenta corregir el peligro de un mundo solo abstractamente futuro, al recurrir a las dimensiones del origen y de la historia.

Otro rasgo típico de esta nueva teología del mundo brota de la integración en ella de las promesas escatológicas de la tradición bíblica (paz, justicia, reconciliación) a cuya luz aparece su distancia de aquello que debe ser, su provisionalidad y la urgencia de su remodelación. Las promesas de la revelación son, por tanto, bajo las condiciones concretas del presente, imperativos críticamente liberadores, que muestran la contradicción del ideal con el mundo existente. La realidad ahora ya no se entiende reflexionando e imaginando, sino que solo puede realizarse en la activa transformación del mundo. Por ello la escatología cristiana es productiva, creadora y en activa expectación.

Finalmente la presente comprensión teológica del mundo incorpora una nueva corrección en otra dirección. El mundo es la creación y el cosmos en su totalidad. Con otras palabras, la naturaleza reprimida y manipulada exige sus derechos. El concepto de mundo de la Gaudium et spes no ayuda a comprender la realidad del mundo como "creaturalidad" y manifiesta un déficit serio respecto a las exigencias de la ecología. La conservación de la naturaleza no humana y de las condiciones de vida apenas tienen lugar en esta concepción del mundo ${ }^{33}$. La Constitución pastoral fue pensada en la cultura del desarrollo, pero desde los años setenta se ha tomado conciencia cada vez más viva de la limitación de los recursos del planeta. En este punto concreto la Gaudium et spes es un documento de ayer. Hoy la teología se ha abierto a la dimensión ecológica, de salvaguarda del planeta tierra, de solidaridad con el futuro. La primera encíclica original y exclusiva del papa Francisco es mucho más que un documento sobre ecología, es una llamada de atención sobre la vida humana que estamos configurando en nuestro planeta.

${ }^{33}$ Cf K. LeHMANN, 1993 Glauben Bezeugen, Gesellschaft gestalten, Friburgo de Brisgoria, Herder, 137-169 
El Papa habla de la creación para hablar de la persona humana y así hablar de Dios. Está por ver si esta encíclica "green", que plantea la espinosa cuestión del cambio climático, responsable de la malnutrición, empobrecimiento, degradación y violencias ejerce una presión eficaz sobre los grandes de la tierra.

El panorama de los cambios descritos muestra los vacíos de la Constitución pastoral. Ciertamente no era su responsabilidad agotar y desarrollar en particular las mencionadas dimensiones del concepto de mundo. Ella de hecho solo resaltó algunas perspectivas y así favoreció indirectamente algunas tendencias que luego han reclamado su corrección. La teología de momento solo le ofrecía bocetos reducidos para un concepto teológico más pleno de mundo. Una reflexión teológica general sobre el concepto de mundo y más aun sobre la relación entre la Iglesia y ese mundo está todavía por llegar.

\subsection{Relectura de la Gaudium et spes a la luz de su recepción}

La consecuencia de lo dicho es que hoy día debe leerse la Constitución pastoral a la luz de la historia de la recepción durante estos cincuenta años, cuyo proceso debe estudiarse críticamente descubriendo los puntos de vista que han ido sucediéndose. Indicamos unos criterios para tal relectura tanto de carácter formal, como referidos al contenido.

\subsection{Criterios de carácter formal}

1. Es imprescindible interpretar de forma renovada desde las condiciones presentes las intenciones globales que se propuso la Constitución y el texto mismo aprobado. Las dificultades que entonces se encontraron en su redacción deben asumirse positivamente y conceptualizarse como indicadores de problemas para un trabajo teológico que hoy no es menos importante que hace cincuenta años. Hay que mejorar con las correcciones necesarias aquellas dimensiones que quedaron incompletas. Para ello conviene aceptar la forma provisional e inacabada del texto conciliar y ha de evitarse su fijación intocable.

2. Por esa razón se deben revisar y analizar algunos textos o enunciados que contienen varios estratos redaccionales, corresponden a la tensión de aquel momento y muchas veces parecen incluso contradictorios. Quizá sea el "ethos" del texto más importante que sus soluciones. Hay que favorecer 
una reflexión permanente sobre su orientación central. La recepción futura no debe olvidar aquellas dimensiones del texto conciliar que hasta ahora se han considerado opuestas a la conciencia contemporánea y por ello se han marginado. Desde la perspectiva de la recepción un trabajo serio con la Constitución pastoral debe hacer valer los puntos de vista hasta ahora no integrados.

3. La Constitución pastoral es un documento abierto que fue asumido por el Concilio conscientemente en una forma provisional y no cerrada y muchos de cuyos impulsos están sin agotar. En razón del apremio de tiempo hubo problemas que se trataron sin profundizar, con evidentes faltas de equilibrio. En consecuencia la presentación de las cuestiones y necesidades compromete también a la lglesia actual y futura. Por eso la Gaudium et spes exige un nuevo comienzo.

4. "Diálogo" y "solidaridad" son dos conceptos que configuran juntamente un eje central, una perspectiva que recorre toda la Constitución. Aunque esas dos palabras fundamentales siguen teniendo el peligro de convertirse en eslóganes, sin embargo deben pensarse conjuntamente una y otra vez y cimentarse más profundamente. La historia de la recepción nos enseña que ambas perspectivas no pueden reemplazarse.

\subsubsection{Criterios referidos al contenido}

Hay también algunos contenidos de la Constitución que necesitan revisión o complementación.

4.3.2.1. La comprensión del mundo debe contar mucho más que hasta ahora con la realidad llena de tensión entre historia y sociedad, entre persona humana y naturaleza. La asunción de la "mundanidad" del mundo no deroga su constitución histórico-salvífica. No existe un mundo teológicamente neutral; no puede ignorarse el carácter permanente decisorio de mundo e historia. El mundo o está ya abierto al Dios más grande, incluso si no lo sabe, o se ha cerrado a Él. Por ello están estrechamente vinculados ética y teológicamente el concepto de responsabilidad histórica y el pensamiento de juicio. Este planteamiento ampliado significa que las estructuras del mundo deben ser consideradas mucho más en su condición ambivalente, por decirlo así "mezclada": entre bueno y malo, entre inmanente y trascendente. La ambivalencia de la modernidad debe 
reconocerse más profundamente, tomarse más en serio y reajustarse más a fondo. En definitiva debe reflexionarse sobre lo contradictorio de todas las estructuras, lo cual se contrapone a la idea de una ingenua transformación permanente hacia lo bueno ${ }^{34}$.

4.3.2.2. Lo dicho nos conduce a recordar que la cruz de Jesucristo debe mantener una significación mucho mayor y ocupar un lugar central e irrenunciable en el cumplimiento de la tarea cristiana en el mundo: qué sentido tiene ser entregado a una realidad fatal e inevitable, la experiencia del sufrimiento, de la inutilidad, del fracaso. Sin embargo, precisamente por eso el cristiano, que vive una esperanza contra toda esperanza, no debe dejarse desalentar. La verdadera, desinteresada y únicamente exitosa transformación del mundo a la luz del evangelio sucede en la pasión del amor, en la "civilización del amor", como dijo Pablo VI. Cuanto más estrechamente se vinculan el cristiano y la Iglesia al centro de la fe, tanto más audazmente puede su valentía convertirse en transformación del mundo.

4.3.2.3. La lglesia y el mundo no pueden diferenciarse netamente la una del otro. Están trenzados en la creación y en la historia de la salvación o de la condenación. No se los puede cortar limpiamente. Porque el Espíritu de Dios sopla también fuera de la Iglesia, en el mundo y la lglesia misma es hasta el fin de la historia un trozo del mundo. El mundo es para el cristiano irreductiblemente y de forma dialéctica ambas cosas, patria y destierro. Por eso no hay un sí al mundo por parte de la fe, que la asimile a él. Quien apuesta por el mundo no de forma absoluta, o no lo diviniza, puede afirmarlo con mayor profundidad. Ya expresó todo esto de una forma resumida, acertada y válida para hoy un cristiano del siglo II: "Tal es el puesto que Dios les señaló (a los cristianos) y no les es lícito desertar de él"35.

\footnotetext{
${ }^{34}$ Aquí habría que hacer una reflexión acerca de esta contradictoriedad del mundo y su carácter de tentación. Cf. J. B. METz, "Concupìscencia", en H. FRIES, director (1966) Conceptos Fundamentales de Teología, I, Madrid, Cristiandad, 255-264.
}

${ }^{35}$ Discurso a Diogneto, en D. RUIz BUENO, editor (2002) Padres apostólicos y apologistas griegos, Madrid Católica (BAC) 657. 


\section{Gaudium et spes replantea el tema eclesiológico de la recepción}

La historia de los concilios da testimonio de que la dialéctica de su aplicación sufre fuertes resistencias y bastantes dilaciones. Los historiadores de la Iglesia saben que los períodos de recepción de los concilios siempre han sido amplios y que muy a menudo el período sucesivo a su clausura se ha distinguido por movimientos e intentos claramente contrarios a las deliberaciones conciliares. Estas deliberaciones, que hubieran podido ser de gran importancia dinámica e instructiva en la vida de la Iglesia, no reciben ningún relieve o, más aun, se retorna a la situación precedente.

Por una parte, no es fácil la recepción de un concilio como este, que fue de actualización y de reforma de la Iglesia. Los tiempos de realización en tales casos son muy largos. El proceso apenas ha comenzado; conlleva el descubrimiento de riquezas antiguas y nuevas, como ha sucedido después de los grandes concilios. El vuelco que se está dando es complejo y gradual; el Concilio solo puso las premisas y señaló el comienzo. Se necesita tiempo para asimilar la profunda experiencia conciliar.

Por otra parte, el hecho insoslayable de la recepción del Concilio por una comunidad cristiana cambiada profundamente en un plazo cronológicamente muy breve plantea cuestiones bien diferentes de las que se plantearon en la recepción de otros concilios. La nueva generación de creyentes, que no ha vivido el Concilio como acontecimiento fundante de su identidad cristiana, es muy distinta de aquella que fue su protagonista. Ha cambiado radicalmente la situación de hoy respecto a una Iglesia tal como fue en la época preconciliar, rica en practicantes, poderosa, con un papel en la sociedad -reconocido o criticado.

En lo que se refiere a Gaudium et spes su radical novedad nos obliga no solo a captar sus aportaciones concretas más fecundas, las líneas de fuerza del pensamiento y las indicaciones operativas que contienen sus decisiones, sino-cosa mucho más importante- sacar de ellas también una indicación global para caminar hacia el futuro.

\section{I.Actualización acrecentadora de la enseñanza conciliar}

Gaudium et spes, razonablemente hablando, no podía responder de manera satisfactoria a los múltiples interrogantes que había planteado la transformación histórica y antropológica de la llustración y que habían sido ahogados durante demasiado tiempo. El debate conciliar consiguió llegar al consenso acerca de las indicaciones de fondo sobre la dirección que debía asumir la reforma, pero no decidió reformas concretas verdaderas y propias; solo expresó un proyecto ideal 
hacia el que moverse. Su realización efectiva exigía profundizaciones de carácter teórico y pastoral, relativas a la interpretación de los signos de los tiempos, que estaban por producirse. La Constitución pastoral dio un enfoque para responder a las necesidades del aggiornamento; pero no percibió las complejas cuestiones teóricas que muchas respuestas conllevaban objetivamente. Su texto no propone fórmulas mágicas para ponerse en práctica mecánicamente. Más bien debe ser interrogado de manera crítica y "reescrito" ininterrumpidamente según cada momento histórico.

Frente a la mentalidad católica anterior al Concilio según la cual la doctrina estaba fijada de una vez por todas y plenamente desarrollada, de forma que nada podía cambiarse, los padres conciliares se manifestaron claramente a favor de la evolución y la actualización doctrinal (GS 91).

Con el término "actualización" no se entiende la simple operación de alinearse respecto a los patrones intelectuales y culturales de hoy, ni una entrega incondicionada al "espíritu del tiempo", cosa que resulta tan sospechosa a los vigías de la ortodoxia. Actualización significa encuentro vital, aunque también crítico, del pueblo de Dios con la totalidad de los fenómenos de la realidad del mundo creado por Dios. Es que el sujeto sobrentendido en esta opción es la Iglesia, una comunidad de vida y de doctrina, con una tarea a realizar; Iglesia que no es un museo que expone objetos antiguos, sino sujeto de la historia y en la historia; $y$, para ser ella misma, debe reaccionar a los desafíos de la historia. En nombre de ese postulado de actualización la Iglesia, fiel a su mandato, debe siempre de nuevo ponerse en camino en el tiempo mirando al futuro. En el Concilio buscó hacerlo; después del Concilio debe proseguir en esa tarea y andar hacia delante.

Después de la conclusión del Vaticano ll es indispensable un proceso de asimilación de sus decisiones, proceso para el cual la eclesiología utiliza un término técnico: recepción. Nos encontramos ante una expresión clave que debe ser bien entendida. Hablamos de una recepción activa más bien que de una exigencia de aplicación soportada pasivamente. Una recepción fundada y animada por el patrimonio de esperanza evangélica que se consolidó en el Concilio.

Recibir el Concilio significa llevarlo a cabo. Es claro que el Concilio quería mostrar a la Iglesia un camino hacia el futuro; limitarlo a texto y doctrina significa negarlo.

La dinámica de la recepción exige hacer una distinción fundamental entre la mera aplicación, aunque sea fiel, de las decisiones conciliares y una interpretación evolutiva de las mismas por el simple hecho del acrecentamiento histórico que se verifica en el curso de su cumplimiento. Porque existe la posibilidad de que, sin traicionar la 
letra, sino más bien para su mejor interpretación, se verifique un acrecentamiento de su mismo valor literal por efecto de interpretaciones constructivas, homogéneas con el propio texto. Hay una distancia cualitativa entre ambas posiciones: la segunda de ellas, la interpretación evolutiva, es la verdadera recepción. Lleva a plenitud y cumplimiento aquella experiencia de búsqueda de nuevas fronteras de la fe que se vivió en el concilio. Es una recepción acrecentadora. $Y$ es diferenciada según las condiciones históricas en las que viven las comunidades.

El posconcilio es la ocasión de que la experiencia conciliar se dilate a toda la realidad eclesial. La historia de la recepción no es una calle de sentido único, ni tampoco es mera historia posterior o "historia de los efectos", sino un proceso que sucede según una dinámica circular y cruzada, una especie de "feed-back", en la que cada creyente y cada comunidad es sujeto y objeto al mismo tiempo. El proceso ilumina de nuevo el texto escrito, injertando y conjugando el fundamento puesto y su efecto ulterior. De esta manera el texto retorna siempre de nuevo y es un impulso permanente en el contexto de la vida eclesial.

Un gran desafío para la Iglesia de nuestro tiempo se encuentra en la verificación de ese empuje para la reforma y la conversión comunitaria, así como en la inserción del mismo en la vida entera del pueblo de Dios mediante una recepción activa y creativa.

En consecuencia, es urgente concebir y realizar con paciente fidelidad una recepción que sea selectiva y creativa a un tiempo. Selectiva, sobre la base de la decantación -hoy posible- de lo que está vivo y de lo que está muerto del Concilio. Creativa, o sea, diferenciada según las diversas condiciones históricas en las que viven las comunidades, "acrecentadora", en el sentido de valorizar y llevar a cumplimiento la experiencia de búsqueda de nuevas fronteras de la fe vivida por el Vaticano II. ${ }^{36}$

La recepción acrecentadora de la que hablamos no significa de ninguna manera ruptura con el acontecimiento conciliar. El debate que se suscitó en el inmediato posconcilio, y en el que posteriormente intervino Benedicto XVI en su famoso discurso a la curia romana en diciembre de 2005, acerca de la discontinuidad o continuidad en relación con la interpretación de la asamblea conciliar, debe considerarse superado en razón de un concepto de tradición como acontecimiento producido por el Espíritu, una nueva epíclesis ${ }^{37}$.

${ }^{36}$ G. AlberIGO (2006) "Il Concilio Vaticano II e il rinovamento della Chiesa": Adista Herder Korrespondenz, 18-III-2006, n 22, 2-7.

37 U. RuH (2012) "Mutige Weichenstellungen", Herder Korrespondenz 66 11, 560-564. 
La tradición cristiana ha expresado de manera reiterada su convicción de la permanente acción del Espíritu de Cristo en la lglesia durante la historia. Y la lglesia es el sacramento de esa acción del Espíritu. En la resurrección de Cristo y el envío del Espíritu ha comenzado ya la nueva condición prometida y esperada; ahí surge el impulso que da sentido a nuestra historia, afirma LG 48. En consecuencia la Iglesia toda, cabeza y miembros, tiene la obligación irrenunciable de asimilar tanto con fidelidad como con creatividad el gran regalo del Espíritu que fue el Concilio. Ese don sigue siendo hoy, como siempre que se trata del Espíritu, un impulso creativo para la Iglesia.

Por ello es necesario reflexionar de manera crítica sobre la actualidad del Concilio, no solo en función de sus textos, sino también de sus desarrollos y del camino histórico de su herencia. El Espíritu de Dios actúa, conduce a la lglesia, no puede ser fijado materialmente, sino que siempre permanece libre en su actuación. El testificó en el acontecimiento conciliar su fuerza innovadora. La tarea de los creyentes en la Iglesia es la de llevar a su término y hacer fructificar las semillas presentes en aquel acontecimiento. Se trata de un movimiento que se desarrolla en direcciones diversas, con etapas más o menos largas o sintéticas y agrupadas, sin que sea perceptible a corto plazo una cosecha de tipo global.

\subsection{La tradición como proceso creativo ${ }^{38}$}

Las anteriores reflexiones acerca de la recepción nos llevan de la mano a la necesidad de aclarar un término teológico crucial cuya entraña ha sido puesta a la luz del día en la reflexión teológica posconciliar, precisamente sobre la Constitución pastoral: el concepto de tradición.

Uno de los elementos decisivos de la secularización que caracteriza el período posconciliar, fenómeno al que antes nos hemos referido, es la llamada "desinstitucionalización" de lo religioso. Este proceso va hoy día vinculado al valor de la realización de sí mismo y conlleva la desarticulación de la alianza de la lglesia con la cultura global y la dificultad de inscribir a los individuos en torno a la referencia común a un sentido dado de lo alto. En definitiva, la desinstitucionalización afecta ante todo a las creencias, lo cual implica una relación nueva de la persona con las

\footnotetext{
${ }^{38}$ Para las siguientes reflexiones nos hemos servido de los amplios trabajos de Ch. THÉOBALD, 2009 La réception du concile Vatican II. I. Acceder á la source, París (Cerf), 665-699; ID., L Hermenéutique de réforme implique-t-elle une réforme de I herméneutique?, en RSR 100/1 (2012), 65-84; ID., "Tradition als kreativer Prozess. Eine fundamentaltheologische Herausforderung", en W.EISELE, C. SCHAEFER, H.U. WEIDEMANN, (Editor), Aneignung durch Transformation. Festschriff fur Michael Theobald. Friburgo (Herder) 2013, 488-508.
} 
tradiciones religiosas y concretamente con la tradición cristiana. La objetivación de la tradición, o sea su cristalización en fórmulas a repetir o a desarrollar según un principio de acumulación, se ha hecho inaceptable en nuestros días. Las indecisiones del Vaticano II a este respecto han marcado profundamente el período posconciliar. Debido a tal indecisión en muchas ocasiones las quejas acerca de la crisis de credibilidad del catolicismo por su falta de adaptación al presente, han sido rechazadas de forma taxativa desde las líneas conservadoras apelando a la tradición o al así llamado "derecho divino". Pero la tradición cristiana no es en primer lugar una enseñanza - incluso si el Catecismo de la lglesia católica nn. 75-83 tiene el peligro de hacerlo entender- sino una vida o un proceso de acontecimientos y de relaciones en sus expresiones tanto singulares como plurales; es un manera de habitar el mundo. Ciertas formas de defender de entrada el carácter "irreformable" de las formulaciones dogmáticas de nuestra tradición (ligadas al contexto cultural de la antigua Europa) o de insistir unilateralmente en la objetividad de un conjunto de verdades a creer tienen el peligro de cerrar el camino de la inculturación.

La recomposición actual de la visión del mundo por parte católica, tal como la propuso la Gaudium et spes y el intento de inscribir la experiencia de fe de hoy en día en la vida humana cotidiana implica una relación creativa con la tradición. Ello no significa que se cuestione lo que llamamos la "irreversibilidad" de la autorrevelación de Dios; solo debe ser resituada. Para avanzar en este sentido es preciso trenzar algunos hilos que están presentes en los textos del Vaticano II pero que no fueron anudados. Ya lo indicábamos al hablar de las debilidades de la Constitución pastoral. Así, por ejemplo, Dei Verbum (7) propone una concepción diríamos "genealógica" de la tradición: designa el proceso relacional de transmisión que une íntimamente lo que ha de transmitirse ("traditum") con aquellos que lo transmiten ("tradentes"), indicando que estos últimos se encuentran en una posición simultáneamente de fidelidad y de aprendizaje ("discere") en relación con la novedad de la situación que es la suya. Gaudium et spes (44), y aún más audazmente Ad gentes $(22,2)$ dan una función constitutiva al contexto histórico de la transmisión y exigen en consecuencia un nuevo examen ("nova investigatio") de la revelación misma, aun reconociendo que nosotros no accedemos a ella más que leyendo las Escrituras, explicadas por los Padres de la Iglesia y por el magisterio. El corazón de la fe es, pues, lo que ese número de Gaudium et spes llama la "facultas exprimendi" que vincula intrínsecamente la capacidad de aprendizaje y la creatividad propia. Por lo tanto, la "irreversibilidad" de la autorrevelación de Dios ha de situarse en el seno de la relación originaria entre Jesús y sus discípulos y apóstoles, relación que suscita la fe. Tal relación no paraliza su creatividad interna, sino que la resucita constantemente, siendo el envío del Espíritu creador la raíz siempre actual de esta inspiración. 
El nuevo subrayado de la relacionalidad entre el evangelio de Dios y su transmisión ("parádosis") complejiza y pluraliza su presencia histórico-cultural, pero le da también un principio de credibilidad, la coherencia entre el fondo y la forma, entre la visión y la práctica, entre aquello que es transmitido y la manera de entregarlo como presencia del Dios santo en la historia.

La consecuencia de esta clarificación del concepto genealógico de tradición es una visión también genética de la misma lglesia. La reflexión teológica acerca de la recepción del Vaticano II y específicamente de la Gaudium et Spes está sin duda llevando al catolicismo a revisitar las primerísimas bifurcaciones que se llevaron a cabo en el cristianismo naciente. El hecho de que las Iglesias de occidente estos últimos años comienzan a descubrirse de verdad como país de misión ${ }^{38}$ hace que adquiera toda su importancia la génesis de la lglesia relatada en el libro de los Hechos, donde se propone una manera de proceder muy alejada del universalismo abstracto, aunque muy sensible al enraizamiento humano y cultural de la fe. Si se da tan gran peso como se merece a la creatividad de la comunidad primitiva, hay que dárselo también a nuestra propia recepción recreadora de esa tradición apostólica en un mundo radicalmente historizado y marcado por una pluralidad de culturas que nos recuerda a un nuevo Pentecostés.

La forma relacional del "kerygma" de Jesús y de la lglesia conlleva la historicidad de toda la tradición apostólica, su vinculación intrínseca a tal lugar ("topos") y a tal momento ("kairós"). Esta afirmación repercute en la comprensión misma de la revelación: la autorrevelación de Dios no existe más que en su recepción histórico-cultural; pero, en razón de la universalidad propia del concepto bíblico de Dios, permanece al mismo tiempo abierta al "Otro" y tributaria de su misterio. Este trasfondo propiamente teológico se transparenta aquí y allí en el texto de la Constitución pastoral, pero el proceso de su recepción apenas ha comenzado.

Es insuficiente lo que solemos hacer habitualmente: yuxtaponer la revelación dada una vez por todas y el diagnóstico de la circunstancia histórica, que siempre es provisorio, aunque sea operado bajo la asistencia del Espíritu Santo. Es necesario integrar en la concepción misma de la revelación, no solo la relación entre Jesús, sus contemporáneos y todos los oyentes posibles, sino más aun su arraigo en un lugar $y$ un tiempo determinados.

Tampoco la expresión "pastoralidad de la doctrina" por sí sola es suficiente para

${ }^{38}$ Aunque tal expresión era común en Europa desde mediados del siglo XX, cf. H. GodiN e Y. DANIEL (1943) La France, pays de mission?, Lyon, l'Abeille 
dar cuenta del proceso de interpretación que vincula el evangelio a la situación y al lugar de cada oyente, si tenemos en cuenta la forma plural que ese proceso toma ya en el Nuevo Testamento. En razón misma de su pastoralidad la doctrina no puede ser comprendida más que como regla de interpretación cuya exigencia de verdad se manifiesta solo cuando se logra distinguirla de la visión unitaria del mundo, que es lo que ha sucedido a lo largo de muchos siglos, sobre todo, en el integrismo católico. Pero en nuestra situación de pluralismo cultural una concepción "ideológica" de la doctrina como instrucción minimiza, o incluso suprime, el arraigo del kerygma en un lugar y en un tiempo salvífico, mientras que la concepción relacional de la que hablamos garantiza "hic et nunc" que el proceso de proclamación y de escucha no se interrumpa prematuramente. En esta función la doctrina no reemplaza a la Escritura, como ha sido muy ampliamente el caso en el integrismo católico, sino que invita a los transmisores a interpretarla en el espíritu de creatividad pastoral, aunque sin ninguna reducción.

Más aún. El problema de la actualización kerygmática de la Escritura no consiste solamente en establecer un vínculo sin más entre el anuncio de Jesús y los signos de los tiempos. El problema se ha radicalizado en estos cincuenta años y la pregunta es: ¿̇cómo vincular los diagnósticos del momento presente, ofrecidos por la sociología y por la historia, perfectamente autónomas en su orden, a una lectura teológica de los signos de los tiempos? La diferenciación de puntos de vista en las ciencias humanas y el conflicto de interpretaciones que ello entraña necesitan un tratamiento verdaderamente nuevo, para el que no tenemos reglas, como decíamos antes citando al prof. J. Ratzinger. Este obstáculo ya fue percibido en el Concilio por algunos padres conciliares, particularmente por los obispos alemanes, pero suena a muerto en la metafísica del integrismo.

Supuesto todo lo anterior, ¿̇qué podemos esperar hoy del Vaticano ll? En esta pregunta hay que percibir la dimensión de "posibilidad" y la llamada a la libertad que ella representa. Esa "gran gracia de la que se ha beneficiado la lglesia en el siglo XX"39 ha relanzado la dinámica mesiánica de la tradición cristiana y ello precisamente en un mundo hoy globalizado y sellado al mismo tiempo por un pluralismo cultural y religioso radical, un mundo en el que el cristianismo, íntimamente vinculado a la cultura mediterránea y euro-atlántica, está amenazado de desaparecer de su tierra de origen. Esta situación paradójica exige que la referencia a la tradición sea resituada, más aun reconsiderada en su globalidad, como el resorte también de la historia de la recepción que la ha revelado como su principal dificultad.

${ }^{39}$ Juan Pablo II, Novo millenio ineunte, 2001 n $^{\circ} 52$ 
Si tomamos nota de los "movimientos tectónicos" de orden cultural, social y eclesial que se han desarrollado a lo largo de estos cincuenta años, hemos de considerar los "umbrales" que la recepción conciliar debe pasar ahora; umbrales seguramente más radicales que los del pasado, a la medida de las pruebas atravesadas por nuestras Iglesias y a la altura de la fuente evangélica y de la promesa mesiánica y escatológica que ampara. Pero ello nos obliga a revisar la percepción del momento presente y el trabajo de reinterpretación que suscita a largo plazo la tradición católica, tal como ha surgido en los debates de estos cincuenta años de posconcilio.

El interés de la hermenéutica contemporánea por la recepción como problema teológico general se ha manifestado a partir de la reflexión sobre la recepción del Vaticano Il y el "re-encuadramiento" como principio interno a la tradición. Se sigue como consecuencia que el contexto histórico-cultural del receptor tiene una función determinante en la escucha y la interpretación del evangelio. Por tanto es imposible comprender la tradición en términos de crecimiento "acumulativo". Toda nueva situación cultural relanza con nuevos costes el proceso de recepción y de interpretación. Ciertamente es imposible "volver atrás de lo que ha sido formulado por el dogma" 40 , pero esta regla nos ayuda poco cuando la misión exige la entrada en una escucha creadora o cuando la diferencia cultural, por ejemplo, entre occidente y el extremo oriente impone verdaderas rupturas.

\section{Ante los desafíos del futuro}

\section{I. Un nuevo modelo de sociedad}

Los cristianos estamos llamados a ser transparencia de Jesús no solo con una vida individual renovada por nuestra coherencia con el don de la gracia que recibimos en el bautismo, sino también con la presencia y la acción en todos los ambientes de vida social, en los múltiples y diversos espacios humanos y vitales en los que se desarrolla nuestra existencia cotidiana.

Es preciso decir de manera explícita que resulta imprescindible buscar un modelo radicalmente distinto de sociedad. Este no podrá construirse de una vez y será el resultado de muchos cambios parciales. Pero es preciso saber a dónde vamos, a dónde tenemos que llegar. Para ello hay que incentivar y apoyar todos los

${ }^{40}$ Comisión Teológica Internacional, La interpretación de los dogmas, 1989, n 87 
movimientos que elaboran un modelo alternativo de sociedad o que luchan para instalar nuevas estructuras inspiradas en un nuevo modelo. Es tarea de los creyentes, avanzando en la línea de la Gaudium et Spes, no solo afirmar los valores positivos del mundo y saberse responsables de toda la creación, sino también -de forma más clara de lo que lo hace la Constitución- ver la existencia crucificada de la persona humana en este muestro mundo amenazado, aceptándolo y cargando con él comunitariamente. Es en este contexto en el que nos corresponde dar testimonio de Cristo como luz del mundo y salvador de toda la humanidad ${ }^{41}$.

En la perspectiva de la misión evangelizadora de la lglesia interesa que los grandes temas de la segunda parte de la Gaudium et Spes entren en la vida cotidiana y se hagan operativos en el campo del testimonio de los cristianos de hoy. Ahora bien, si confrontamos los problemas más urgentes señalados por nuestro documento con aquellos que hoy se nos plantean, vemos que existe gran distancia entre la visión del tiempo conciliar y la del tiempo presente. En realidad la diferencia de visión es coherente con el espíritu del Concilio que nos invita a "aggiornare" nuestra mirada según los nuevos signos que hacen surgir y recomiendan la sensibilidad cultural y el cambio social. En este sentido la celebración de los cincuenta años de la clausura del Concilio no está destinada a agotarse en un recuerdo celebrativo, público y solemne, ni a empobrecerse en la realización de análisis históricos o profundizaciones teológicas - que por otra parte son útiles y necesarios-, sino que debe tener el importante objetivo evangelizador de relanzar el testimonio cristiano en todas sus formas.

Ahora bien, ese objetivo misionero exige para su consecución objetiva el relanzamiento convencido y determinado de protagonismo de los cristianos laicos. Una nueva época del testimonio tiene absoluta necesidad de creyentes apasionados que personalmente y asociados redescubran y profundicen la consciencia del don y de la responsabilidad bautismal en toda su grandeza y urgencia. Retornamos así a una idea eje de toda la enseñanza del Concilio, para quien, antes de cualquier distinción en el interior de la lglesia, ella es, como pueblo de Dios, el sujeto de la misión.

Surge así de inmediato la importancia de la vocación bautismal, de la figura adulta de la fe y de la promoción de la calidad cristiana de la conciencia laical. Esta conciencia, que la Gaudium et Spes contribuyó a que se convierta en patrimonio común de los creyentes de hace cincuenta años, nos viene consignada como una

${ }^{41} \mathrm{~J}$. CombinN, Sinais dos novos tempos. 40 anos depois do Vaticano II, en A. S. MoreIRA (org.), A primavera interrumpida... o. c., 59-66 (65) 
herencia viva que no debemos malgastar sino vivir como una promesa de la que todavía esperamos frutos lozanos en el futuro ${ }^{42}$.

Viene ahora a cuento la tantas veces repetida frase de K. Rahner: "El cristiano del futuro o será un "místico", es decir, una persona que ha "experimentado" algo, o no será cristiano"43. Absolutamente cierto. Pero, jatención!, esa experiencia no ha de buscarse en las alturas, reservadas a algunas elites, sino en los fragmentos de la existencia cotidiana donde la Bondad radical o siempre nueva de Dios no cesa de manifestarse a aquel que se deja enseñar por la fe para lograr percibirla.

\subsection{Al servicio del Reino de Dios en el mundo}

La Iglesia debe estar siempre al servicio del Reino de Dios y, por tanto, al servicio del mundo en el que el Reino se instaura. La concentración del Vaticano II sobre la Iglesia, nota distintiva suya sobre otros concilios de la historia, se ha precisado en el sentido de una existencia de la Iglesia toda ella orientada a entregar Cristo a los hombres y a conducir los hombres a Cristo. En ningún caso se trata de autopreocupación eclesial porque para los cristianos comprometidos lo más urgente es el destino de su fe en las circunstancias presentes, sociales culturales y religiosas.

Este rasgo esencialmente relacional de la Iglesia y de su acción ha iluminado su rostro de tal forma que ella ha adquirido una clara conciencia de su natural e irrenunciable dimensión misionera. Esta dimensión aparece ya desde los primeros compases del documento (GS 3). La actitud de servicio señalada al final del número citado hunde sus raíces y encuentra su explicación en el misterio mismo de la Iglesia, "signo e instrumento de la íntima unión con Dios y de la unidad del género humano" (LG 1). Es precisamente esta su específica identidad y misión lo que la pone al servicio del mundo y en diálogo con el mundo. Un diálogo que lejos de ser una destreza táctica o pura argucia misionera, constituye la forma propia e insustituible del servicio que la Iglesia a imitación de su Señor y Maestro está llamada a prestar al mundo y a la historia.

Cincuenta años después quizá hay que repensar de forma más valiente la misión de la Iglesia y de los cristianos en el mundo interpretándola como inmersión en

${ }^{42}$ D. TettamanzI, La missione della Chiesa nel mondo di oggi, I. c.

${ }^{43}$ K. RAHNER (1969) "Espiritualidad antigua y actual", en: Escritos de Teología, VII, Madrid, Taurus, 15. 
él al servicio del reino de Dios, como signo e instrumento suyo. Signo, es decir, anticipación, su encarnación inicial aunque real, que con su mismo existir y estar dentro de la sociedad está llamada a mostrar cuál es el verdadero modo de vivir según los valores del Reino. Instrumento, es decir, una Iglesia llamada a ayudar a la sociedad entera a redescubrir, valorizar y promover todo aquello que de bueno está inscrito en su interior; y ello incluso ofreciéndole indicaciones o corrigiéndola. Ahí, precisamente en eso bueno está llamada a reconocer las "semillas del Verbo", signos de la presencia de Jesús en el mundo, reverberaciones de la acción potente del Espíritu de Dios, y a darles un nombre, el nombre propio de Jesús y de su Reino.

Cuando se habla de la presencia de los cristianos en el mundo, el discurso a menudo, todavía hoy, es mal entendido como si se tratase de un proyecto de ocupación de la sociedad. No es así. La misión de la lglesia y de los cristianos debe ser modelada sobre la misión misma de Cristo, que no tiene los rasgos de una conquista, sino los de un amor que sirve y se entrega, que es de orden religioso, no económico, social o político (GS 42).

Por tanto, lo que cuenta es la calidad del testimonio creyente en el interior de las formas de la vida y de la convivencia civil. Es la capacidad de transformar las relaciones humanas y sociales haciéndoles cada vez más humanas y humanizantes, y no la ocupación de los espacios sociales y el deseo y la voluntad de tener más autoridad o categoría. Todo ello conlleva que en el interior de los pliegues de las relaciones interpersonales y de las diversas estructuras y organizaciones sociales, los lenguajes, las reglas y las costumbres del vivir humano puedan abrirse cada vez más sobre el horizonte de un destino trascendente, sin el cual la persona humana sería un puro instrumento del poder o un simple mecanismo de una tecnología globalizada y la misma sociedad no estaría verdaderamente al servicio de la persona, de su dignidad, de la justicia y de la paz.

\subsection{Las instituciones del pensamiento}

A cincuenta años de la finalización del Concilio advertimos que la presencia de los creyentes en el mundo debe ser relanzada no solo con valentía, sino con inteligencia previsora. La llamada que no puede desatenderse es la de desarrollar una reflexión seria y profunda acerca de los espacios en los que debe verificarse el ejercicio cotidiano del testimonio cristiano de Jesús resucitado, esperanza del mundo.

Es un ejercicio que debe iniciarse ante todo mediante un análisis cultural que no se limite a caminar detrás de las situaciones. No podemos olvidar que a la dimensión cultural del testimonio cristiano pertenece la interpretación del tiempo 
presente y la prefiguración de nuevos recorridos para el futuro. Desde esta óptica todas las instituciones del pensamiento cristiano, en especial las universidades católicas, deberían advertir cada vez más la urgencia y la necesidad de dedicar, tanto individualmente como mediante un mayor diálogo y confrontación entre sí, nuevos espacios a la comprensión del presente a la luz de la fe.

Esta dimensión de la comprensión del tiempo actual y de sus dinámicas culturales es una tarea fundamental e irrenunciable para preparar de modo coherente una acción cristiana verdaderamente consciente y responsable. La elaboración cultural debe marcar hoy el paso, por delante de preocupaciones más inmediatas y de la facilidad de soluciones de corto aliento. Aquel arrojo apasionado de muchos católicos del tiempo del Concilio y del inmediato posconcilio, necesita hoy una continuación mucho más vigorosa y cuasi profética.

Según la perspectiva propuesta, el creyente debe saber leer las modalidades de la vida actual, respetar las reglas que presiden la convivencia civil y la organización social y política y producir una clarificación acerca de la idea de persona humana y de sociedad a la luz de la razón y específicamente de la fe. Es esta una operación indudablemente compleja que debe implicar a todos los creyentes, llamados a discernir y a actuar, ciertamente bajo la animación y la guía de los pastores, pero también poniendo en juego su inderogable responsabilidad y sus específicas competencias y experiencias de vida.

La indicada tarea del discernimiento revela toda su importancia si consideramos la presencia concreta y la acción de los cristianos en la vida social y política, así como sus opciones. Efectivamente, si de un lado los creyentes, individualmente o asociados, no pueden no reconocer las exigencias que derivan del evangelio y de la fe $y$, por tanto, no pueden obrar sin dejarse siempre guiar por la conciencia, por otro lado, saben que las opciones concretas para actuar con responsabilidad en la historia no derivan ni directa ni exclusivamente de los contenidos de la fe, sino que dependen también de la lectura debida e interpretación de la historia, así como de la escucha atenta de los impulsos que el Espíritu de Dios siembra en las vicisitudes del mundo.

Es grave la responsabilidad que corresponde a las universidades de la lglesia en este proceso. Sólo una teología libre podrá realizar tal tarea, hablando con verdad y sinceridad por encima de las presiones y el miedo instalados en la lglesia, introduciendo los nuevos temas que se vayan planteando. La lglesia no alcanzará ningún resultado ante la nueva cultura global si sigue amordazada por presiones y coacciones de continuidad y no está dispuesta a comprender y explicar lo nuevo, lo inesperado, las rupturas. Una 
característica fundamental de tal estilo de actuación ha de ser la confianza fundada en la gracia victoriosa de Cristo, de la que deriva un nuevo empuje para la misión: el mismo que movió a los padres conciliares a derribar los bastiones para hacer de la Iglesia un lugar abierto, donde las personas gozan al respirar porque advierten la presencia del Espíritu que es el principio de la libertad. Del Concilio hemos de obtener fuerza para encaminarnos hacia el futuro; nada de llorar el pasado, sino asumir el vigor entonces sentido. La perspectiva ha de ser estimular a vivir el Concilio, en lugar de limitarse a recordarlo como un acontecimiento fascinante pero ya fuera del tiempo.

Interesarse por la recepción del Vaticano II no es apartar la mirada de los desafíos que se nos plantean en el presente, sino impregnarse con resolución del espíritu del Concilio en el momento en que a los cincuenta años de su final, debemos renovar sus opciones. En relación con la recepción del acontecimiento del Concilio hoy está en juego el futuro próximo de la Iglesia. El representa para todos un punto de referencia y la postura que tomemos en relación con él determina el camino que vamos a recorrer. 